\title{
NARRATIVAS EM REDE: ARGUMENTOS COLETIVOS E HISTÓRIAS DE VIDA NA EDUCAÇÃO
}

\author{
Suzana Lopes Salgado Ribeiro \\ Universidade de Taubaté \\ suzana.ribeiro@falaescrita.com.br \\ Patrícia Romana de Oliveira \\ Universidade de Taubaté \\ patriciaromana@hotmail.com
}

\begin{abstract}
RESUMO
$\mathrm{O}$ artigo reflete sobre o conceito de rede e seu uso no fazer da história oral, em especial como forma de registro da história da educação e do patrimônio educativo. Ao apontar como se formam as redes, pensa sobre sua organização, seus argumentos, suas afetividades e seus pertencimentos. Além disso, as redes são apontadas como mais que procedimento metodológico, mas como produção de significados e, por isso, importantes para a constituição do conhecimento. As discussões derivam da tessitura das redes de entrevistas de uma pesquisa de mestrado em Educação. O estudo objetivou a análise da construção identitária de professores na jornada ampliada de escolas de ensino fundamental, considerando as histórias de vida narradas como documentos, que dão visibilidade às percepções dos colaboradores da pesquisa.
\end{abstract}

Palavras-chave: Professores. História Oral. Subjetividade.

\section{NETWORK NARRATIVES: COLLECTIVE ARGUMENTS AND LIFE STORIES IN EDUCATION}

\begin{abstract}
The article reflects on the concept of networking and its use in making oral history as instrument to registrat a history of education and of educational heritage. By pointing out how networks form, it thinks about its organization, its arguments, its affectivities and its belongings. Moreover, the networks are pointed as more than methodological procedure, but as production of meanings and, therefore, important for the constitution of knowledge. The discussions derive from the tessitura of the networks of interviews of a masters research in Education. The study aimed at analyzing the identity construction of teachers in the extended day of elementary schools, considering the life histories narrated as documents, which give visibility to the perceptions of the research collaborators.
\end{abstract}

Keywords: Teachers. Oral History. Subjectivity.

\section{NARRATIVA EN RED: ARGUMENTOS COLECTIVOS E HISTORIAS DE VIDA EN LA EDUCACIÓN}

\section{RESUMEN}

El artículo refleja sobre el concepto de red y su uso en el hacer de la historia oral. Al señalar cómo se forman las redes piensa sobre su organización, sus argumentos, sus afectividades y sus pertenencias. Además, las redes se apuntan como más que procedimiento metodológico, pero 
como producción de significados y, por lo tanto, importantes para la constitución del conocimiento. Las discusiones derivan de la tesitura de las redes de entrevistas de una investigación de maestría en Educación. El estudio objetivó el análisis de la construcción identitaria de profesores en la jornada ampliada de escuelas de enseñanza fundamental, considerando las historias de vida narradas como documentos, que dan visibilidad a las percepciones de los colaboradores de la investigación.

Palabras clave: Profesores. Historia Oral. Subjetividad.

\title{
RÉCITS DE RÉSEAU: ARGUMENTS COLLECTIFS ET RÉCITS DE VIE EN ÉDUCATION
}

\begin{abstract}
RÉSUMÉ
L'article se penche sur le concept de réseau et son utilisation dans l'histoire orale. Em indiquant comment les réseaux se forment, il pense à son organisation, à ses arguments, à ses affectivités et à ses appartenants. De plus, les réseaux sont désignés comme étant plus que des procédures méthodologiques, mais comme une production de significations et, par conséquent, importants pour la constitution de connaissances. Les discussions découlent de la tessiture des réseaux d'interviews d'une recherche de master em éducation. L'étude visait à analyser la construction identitaire des enseignants lors de la longue journée des écoles élémentaires, en considérant les récits de vie comme des documents, qui donnent une visibilité aux perceptions des collaborateurs de la recherche.
\end{abstract}

Mots-clés: Enseignants. Histoire orale. Subjectivité.

\section{INTRODUÇÃO: CONCEITOS E FUNDAMENTOS}

As redes de entrevistas, objetos de reflexão do presente artigo, constituíram-se no processo de desenvolvimento de uma pesquisa, que fez do registro de história oral de vida sua escolha metodológica. Neste artigo, estas redes se apresentam como alternativa para o registro de fontes para a escrita da história da educação e para a valorização do patrimônio educativo. As narrativas compartilhadas pelos docentes formaram o conjunto de documentos que nos ajudaram a compreender como as experiências docentes, ocorridas em um contexto diferenciado de educação, denominado "jornada ampliada", em um município do Vale do Paraíba paulista, cooperaram no processo de construção da identidade destes profissionais.

A pesquisa de abordagem qualitativa seguiu premissas de integralidade e de subjetividade e elegeu como fundamental o que e como os docentes escolheram narrar. Assim, as narrativas oportunizaram visibilidade aos docentes que atuam na "jornada ampliada", ou seja, no período destinado para as atividades diversificadas nas escolas de tempo integral, e que, portanto, encontram-se deslocados daquilo que se entende por ensino regular nas escolas. 
Como a pesquisa vem sendo desenvolvida em um mestrado profissional em educação, entendemos que a experiência das pesquisadoras junto à educação e à história oral, são elementos centrais e constitutivos das subjetividades que indicaram caminhos temáticos e metodológicos para a construção de conhecimento. Esta reflexão interessa na medida em que se pode compreender que a constituição das identidades expressas pela rede de entrevistas envolve mais que apenas os entrevistados, mas estabelecem relações entre eles mesmos e com os entrevistadores.

Redes de entrevistados, para a metodologia de história oral que norteou esta pesquisa, é conceito que pode ser definido - a partir de trabalhos como Meihy (1991, 1998, 2005) e Meihy e Ribeiro (2011) - como grupos de pessoas a serem entrevistadas indicados por colaboradores da pesquisa. As redes se estabelecem no decorrer do trabalho de acordo com a aceitação e adesão das pessoas indicadas. No presente trabalho, foi possível definir duas redes que se entrecruzaram. Cada uma delas auxiliou na especificação do tema, agregando argumentos e ampliando justificativas da importância da educação integral.

Os profissionais entrevistados para a pesquisa foram chamados de colaboradores, como sugerem os textos de Meihy (2005). A atribuição de tal denominação fundamenta-se no reconhecimento da condição destes sujeitos no desenvolvimento deste estudo, pois a colaboração ocorreu na produção dos documentos, sem os quais seria impossível a realização da pesquisa. Assim, esses colaboradores ofertaram seu tempo e construíram de forma dialógica suas narrativas de vida. Além disso, no que toca a questão das redes, participaram ativamente em sua confecção, indicando entrevistados e fornecendo credenciais e contatos para as entrevistas. É preciso ter claro que os docentes, indicando outros colegas, teceram a estrutura para a pesquisa e interferiram nos contornos do estudo.

Desta maneira, gostaríamos de destacar que o documento final é resultante do diálogo entre pesquisadoras e colaboradores (todos imersos em intenções). Acreditamos na criação de um documento pleno de intersubjetividades, destacando que esta relação é vista como motivadora e explicadora de afinidades e de identidades, que compartilhadas, permitiram a tessitura dos documentos, resultantes de diálogos e de escutas. Cabe, assim, refletir sobre intersubjetividade, à medida que nas narrativas registram subjetividades na relação entre dois sujeitos.

Nas palavras de uma de nossas colaboradoras "o outro te traz alguma coisa e você precisa entender o seu ponto de vista! Esse movimento de sair do seu corpo e ir para ótica do outro é de extrema importância!" (Cristina Luz). Retomamos, assim, as reflexões de Buber $(1977,1982)$ sobre a palavra proferida em busca de diálogo. Diálogo este que só pode acontecer 
na relação de dois seres humanos, no mundo do "entredois". Este "entre" não é esfera espacial, e, sim, ontológica, que dá condição da relação dialógica acontecer, na medida em que a palavra, depois de proferida pelo "eu" vai ao encontro do "tu”, mas neste caminho deixa de pertencer a um e a outro. Na relação eu-tu, o "entre" é o intervalo de revelação de sentidos e significados que, em um diálogo autêntico, permitirá perceber o outro em sua alteridade. Além disso, as identidades - sentidos de pertencimento a grupos ou de localização no tempo e no espaço - não é mais vista como a de um sujeito único e universal, e sim, composta por diferenças e diversidades culturais que acontecem em diferentes graus (HALL, 2006).

Abordamos, portanto, a intersubjetividade como elemento fundamental para a composição das narrativas, posto que escritas em diálogo permitiram a compreensão de um mundo do "entre". Ao mesmo tempo trabalhamos com o conceito de subjetividade, pois compreendemos que mesmo a subjetividade sendo dimensão íntima de cada sujeito, ela é variável e instável. É produzida de forma polifônica e coletiva (GUATTARI, 2012), e no contexto contemporâneo passou a ser dimensão inseparável da vivência humana, mesmo nos processos de objetivação profissionais como os estudados neste artigo. Nesta medida, é necessário valorizar o trabalho do professor e seu papel para a escrita de uma história da educação e da instituição escolar que dê conta da especificidade das experiências de vida dos sujeitos envolvidos neste contexto.

Cabe pontuar, portanto, que a reflexão acadêmica sobre a subjetividade ganhou força frente à contemporaneidade em trabalhos como o de Deleuze e Guattari (1995, 2000, 2012) no âmbito da teoria mais geral. Também no que tange à área da educação, a subjetividade ganha centralidade em trabalhos como os de Nóvoa (1991, 1995), ao destacar a importância das histórias de vida dos professores para a construção de saberes docentes - e porque não dizer para a constituição de uma história da educação e do patrimônio educativo. Neste sentido, defende-se que a história oral, seja campo auxiliar na tarefa de composição documental e de análise para a escrita da história de nossas instituições escolares e de nossas práticas educativas. Com isso, pode-se ver uma "guinada subjetiva" tomar corpo (SARLO, 2007), como resistência a um movimento de homogeneização e produção de conhecimento mais próximo às experiências.

Desde Benjamin, compreende-se que o narrador, por poder "recorrer ao acervo de toda uma vida", que inclui também a experiência alheia, conta toda sua vivência e "sua dignidade é contá-la inteira” (BENJAMIN, 1985, p. 221). Assim, também parece expressar Nóvoa (1995), ao dizer que a formação docente não pode separar a pessoa do professor, entendendo que vida e profissionalidade são dois aspectos da formação identitária dos professores. Tais questões 
foram muito marcantes nas entrevistas que compuseram esta pesquisa. Além disso, na reflexão sobre a vivência e sobre a construção identitária por intermédio das narrativas, admite-se como um exercício de validação de diferentes versões e sujeitos e confere às histórias cotidianas status de documentos. Assim, neste artigo, encontram-se as razões da articulação das redes como recurso teórico e metodológico para o estudo.

\section{HISTÓRIA ORAL E TESSITURA DAS REDES: CONTEXTO E COMPOSIÇÃO}

$\mathrm{Na}$ busca de definições para o trabalho com história oral pudemos encontrar enquadramentos adequados. Segundo Meihy e Holanda (2007, p. 15), "história oral é um conjunto de procedimentos que se inicia com a elaboração de um projeto e que continua com o estabelecimento de um grupo de pessoas a serem entrevistadas". História Oral pode ser definida, ainda, como um trabalho de pesquisa atento ao diálogo e à colaboração de sujeitos, que considera suas experiências, memórias, identidades e subjetividades, para a produção do conhecimento. Neste trabalho acontecem intervenções e mediações e se dá a construção de narrativas. A partir do registro de tais narrativas e de sua transposição do oral para o escrito é possível sistematizar estudos referentes à experiência de pessoas, de grupos e de instituições (RIBEIRO, 2016). Neste sentido, a linha teórica de trabalho apontada por Meihy se destaca e se caracteriza como referencial para o presente artigo.

Desta linha destaca-se também o desafio de trabalhar com um tipo específico de história oral. A proposta de se realizar este trabalho à luz das premissas da história oral de vida contou com diferentes ponderações. Considerava-se fundamentalmente necessário que houvesse cooperação quanto à integralidade das narrativas dos entrevistados, pois a "história oral de vida tem feições mais biográficas e obedece sempre à sequência dos acontecimentos da vida: infância, juventude, maturidade" (MEIHY; RIBEIRO, 2011, p. 97). Assim, a pesquisa também escolheu utilizar-se da compreensão as experiências narradas como matéria prima para as análises, em atenção às subjetividades. Desta forma, portanto, a integralidade e a subjetividade são elementos considerados essenciais.

O público eleito para essa pesquisa também se configurou como um fator favorável à escolha da metodologia, pois sua composição foi dada por professores que vivenciam ou vivenciaram um contexto profissional específico. Em 2009, o município estudado do Vale do Paraíba paulista implantou, em algumas das suas escolas de ensino fundamental, um projeto que previa aumento na carga horária diária de atendimento dos alunos matriculados. O projeto estendia o tempo escolar oferecido, o que foi denominado "jornada ampliada", e tornou-se 
cenário de atuação para esses professores. Além de engrossar o quadro docente da unidade escolar, os profissionais desempenhavam sua profissão em uma dinâmica diferenciada, à luz da constituição de novos olhares sobre a educação, exigindo deles outros saberes e formas de agir, conformando formas de ser que mesclam saberes da vida e do currículo na docência (NÓVOA, 1995).

\footnotetext{
Fomos aprendendo bastante juntos! Tinha que pesquisar. Não tinha como trabalhar sem pesquisar e buscando algo diferente para levar para as crianças. Então, tanto pesquisava na internet, quanto nas experiências que tinha vivido na faculdade e fora dela, nos lugares que fui passear, nas vivências que tive no magistério ou de outras épocas. Acabei trazendo tudo para a minha prática. (Cecília).
}

Pode-se dizer que a vivência da experiência de aprender e se desafiar juntos imprimiu nas histórias e nas práticas dos professores do grupo estudado, traços comuns que delineiam memórias coletivas (HALBWACHS, 2013) e identidades sociais (POLLAK, 1992) e de certa maneira identidades culturais na diferença (HALL, 2000). O empenho em compreender o processo de construção das identidades destes profissionais pela contribuição destas vivências desvelou-se, no registro de histórias orais de vida. Isto, pois, possibilitou ouvir (em um diálogo autêntico, BUBER, 1982). A metodologia da história oral oportunizou que fossem ouvidas as vozes aos diferentes e se apresentou como um "campo aberto à produção de conhecimentos sobre diferenças" (MEIHY; RIBEIRO, 2011, p. 28). Desta maneira, entendemos que a história oral de vida, por se caracterizar como biográfica, subjetiva e reveladora de diferenças, compunha melhor com uma pesquisa que pretende compreender como atuação profissional se envolve na composição de identidades para cada sujeito entrevistado respondendo metodologicamente a questões teóricas apontadas (HALL, 2000, 2006; GUATTARI, 2000, 2012; NÓVOA, 1995).

Tendo em mente o crescimento de pesquisas sobre a relação do trabalho docente com a composição de uma identidade profissional, estabelecemos o tema e a comunidade de destino da pesquisa, como sendo um grupo amplo de profissionais que atuam na educação, mas que não fazem parte dos processos da educação regular. Definiram-se os profissionais que trabalhavam na jornada ampliada como a colônia - ou se preferirem a população - deste estudo. Considerou-se como critério de inclusão nas redes de entrevistados que as entrevistas fossem realizadas com professores com no mínimo dois anos de experiência nesta dinâmica, para mérito de consistência. Este critério se justifica uma vez que se lançava questões a respeito da contribuição desta experiência sobre seu percurso construtivo de identidade. Com base no ano letivo de 2017, cerca de 59 docentes atendiam ao critério. Dada a quantidade de profissionais que se enquadravam aos critérios definidos no projeto de pesquisa, a profundidade das 
entrevistas, o tempo disponível para a análise dos dados coletados, propôs-se a ouvir seis histórias de vida, que se traduziram no conjunto documental desta pesquisa.

Entretanto, outra questão ainda se fazia: como se daria a escolha destes seis profissionais que comporiam esse universo? Diversos critérios poderiam ter sido eleitos para que se elencassem os seis nomes. Porém, premissas da pesquisa, nortearam os rumos dessa composição. Protagonistas na constituição dessa pesquisa, os docentes que construíram dialogicamente suas narrativas de vida também cooperaram com a forma de composição da rede das entrevistas. Assim, devemos entender que parte dos argumentos dos entrevistados se revela na tessitura da rede, que foi compartilhada entre pesquisadoras e "colaboradores" (MEIHY; RIBEIRO, 2011, p. 22). Compreendemos que a cada indicação, nos afastávamos de um emaranhado de possibilidades de representações e nos aproximávamos de uma linha argumentativa com pontos de intersecção que desdobravam argumentos e conectavam vidas. Nessa teia composta pelos entrevistados se revelavam tramas cujas narrativas de certa maneira se complementam.

Desta forma, os docentes, compuseram suas narrativas/documentos e foram chamados a indicar um colega a colaborador com o estudo. Cabe ressaltar que no momento da solicitação da indicação pelo docente, não foi imposto nenhum critério quanto a sexo, tipo de contratação profissional, formação ou unidade escolar de atuação. $\mathrm{O}$ docente indicado apenas deveria ter no mínimo dois anos de experiência na jornada ampliada. A lembrança dos nomes para a indicação surgia sempre associada à relevância do colega dentro do contexto estudado, com julgamento de que poderiam ser significativos colaboradores e que ofereceriam consistentes histórias de sua experiência. Mas, para além disso, não podemos ser ingênuos. A indicação de entrevistados é também expressão da subjetividade. De uma subjetividade que se expressa em indícios compartilhados em várias vozes das quais Cecília é representante:

\footnotetext{
Como foi uma base que tive, bem no início da minha formação. A gente não se enxergava como o outro professor. No começo, eu não entendia porque os professores achavam tão difícil fazer da forma que eu fazia. Não entendia por qual razão pensavam tão diferente de mim. Está enraizado em mim. A gente internaliza esse trabalho e essa visão global do aluno, e, até de nós mesmos. (Cecília).
}

A professora parece apontar que os profissionais que não estavam inseridos no projeto da jornada ampliada tinham uma identidade diferente dos que nela estavam inseridos. Mais que isso, as diferenças de formas de ser e atuar dificultavam compreensões, mas também se “enraizavam”, ou seja, marcavam pertencimentos. Em outras palavras, pode-se dizer que esses argumentos, que presentes em outras entrevistas, alicerçam uma memória coletiva 
(HALBWACHS, 2013) e também uma comunidade. Lembrando que, segundo Bauman (2003), comunidades são significados subjetivos atribuídos pelos sujeitos aos grupos aos quais pertencem. Estes significados constroem coerência e produzem sentidos de pertencimento e de continuidade no tempo e no espaço. Ou seja, tais comunidades auxiliam no enfrentamento das turbulências, ao mesmo tempo em que compõe identidades compartilhadas (BAUMAN, 2003) e fortalecem pertencimentos em especial frente às fragmentações das identidades do mundo contemporâneo (HALL, 2006). Turbulência comum na vida de professores são as questões de comportamento relacionadas aos alunos, e sobre isso a professora Flor afirmou: "No projeto de escola integral, com o fato de estarem mais tempo juntos, os alunos passam a entender e a aceitar melhor o outro. Entre os professores também é diferente, porque a relação é de companheirismo, de "estamos juntos", de um depender do outro".

Neste sentido, temos que compreender que a comunidade composta pelas experiências docentes analisadas neste trabalho, são projetos de mudança da realidade escolar e esses professores compõem uma comunidade que valoriza a experiência humana em suas diferenças, que compreende a educação democrática como a coexistência entre diferenças e conflitos que não levem à eliminação do "outro", mas o respeito a sua presença e valorização de sua existência. Um exemplo foi citado pela professora Cristina Luz:

A energia vital para a nossa profissão é a energia dos alunos! Sempre tive uma boa relação com eles e dentro do projeto fui muito feliz! Tinham os conflitos, mas a gente se juntava e resolvia. Na época, a gente também teve uma capacitação para a Justiça Restaurativa. Isso veio a calhar, porque era feita a tentativa de compreender o motivo daquele desentendimento e era pedido para que os meninos conversassem. (Cristina Luz).

Destacada a importância da existência do outro, a decisão metodológica de compartilhar a montagem das redes com os docentes entrevistados foi maneira de assegurar o protagonismo aos profissionais, e garantir espaço de colaboração. As narrativas/documentos, criados a partir dos diálogos, são ao mesmo tempo escolhas narrativas e composições que entrelaçam interesses do pesquisador e dos pesquisados, cujos papéis não mais se posicionam como opostos, do tradicional "eu" e ou "outro" nos quais alteridades por vezes suplantam possibilidades de interação em compreensão mútua. Alteridade que ora elimina a diferença e ora homogeneíza tudo, nos impondo a violência do consenso, do igual, do qual não participa nenhuma alteridade (BAUDRILLARD, 2002), a ponto de as relações perderem qualquer rugosidade, devido a um excesso de igual (HAN, 2015).

A pesquisa mediante aprovação do Comitê de Ética em Pesquisa da Universidade de Taubaté (CEP-UNITAU), previu resguardar a identidade dos participantes da empreitada deste 
estudo. Entre dezembro de 2017 e fevereiro de 2018, seguindo os preceitos da história oral e as etapas recomendadas por Meihy e Ribeiro (2011), os encontros se realizaram para a gravação das entrevistas abertas.

Os primeiros contatos com os professores foram realizados por meio das redes sociais para que se efetivasse o convite, se divulgasse as informações sobre o propósito da pesquisa e se marcasse o encontro, definindo data, horário e local. Neste sentido, outra mediação das redes toma vulto. As redes sociais do mundo digital, estruturadas por algoritmos compõe um duplo que deve ser levado em conta. Na presente pesquisa permitiram o contato com os colaboradores, e sabemos que por meio desses encontros e diálogos estabelecidos, de certo modo criam comunidades virtuais em que semelhantes podem se confraternizar. Entretanto, por outro lado, sobem-se muros de forma a nos isolar das diferenças, nos conduzindo a uma confortável segurança, mesmo que retirando parcela de nossa liberdade (BAUMAN, 2003) e nos colocando em contato com mais do mesmo, nos inundando de uma positividade em que as diferenças e a alteridade podem desaparecer (HAN, 2015).

Como partilhávamos de ideais e experiências em comum, e nos propusemos ao diálogo (BUBER, 1982) desde esse primeiro contato, os docentes entrevistados mostraram-se dispostos e receptivos em participar. Ao serem comunicados a respeito das condições para efetivação do registro de sua história de vida, todos os docentes, mostraram-se agraciados e disseram-se lisonjeados na realização de tal tarefa. A eles, foram asseguradas as informações referentes aos objetivos da pesquisa e o sigilo quanto à sua identificação durante todo o processo.

Os entrevistados definiram o local da entrevista, e outros ajustes foram fruto de consenso de agendas. No início de cada encontro, cuidou-se novamente para serem oferecidas informações quanto ao estudo e à forma da indicação de seu nome, sempre em clima de coleguismo e parceria.

Cada docente também definiu um codinome para ser utilizado afim de que, as relações entre o narrador e a narrativa se mantivesse mesmo que preservada anônima sua identidade. Portanto, a escolha dos codinomes foi pessoal, de dimensão íntima. Os codinomes mantiveramse com referências aos narradores, pois assim como atribuiu-se a ele a liberdade da decisão sobre o que seria narrado ou não, a sua identificação no estudo também ficou a seu cargo, com obediência à mesma premissa. Os encontros, com tons de pessoalidade, proveram, o exercício de ouvir e de narrar, buscando formas de diálogo autêntico em que a intersubjetividade pudesse se expressar de forma livre e respeitosa (BUBER, 1977, 1982). Na sequência, o material gravado em áudio foi transcriado para o exercício da análise pretendida no estudo. 
Pleiteando garantias à diversidade, a rede de entrevista foi realizada em duplicidade, cada uma com seus argumentos. Desta forma, tomou-se como ponto de partida dois professores, com formação e experiência distintas, bem como condição atual também diferente. O primeiro, ainda com seu cotidiano envolvido, atuando na jornada ampliada, e, o segundo profissional que por alguns anos já não desempenha sua profissão de forma vinculada ao referido projeto.

Com isso tentamos assegurar, mesmo frente aos alinhamentos de experiências profissionais, possíveis diferenças de pontos de vista e percepções. Isto reforça a premissa da organização de redes complementares, que ao apresentar seus argumentos possa estimular diálogos e dissensos, pluralizando, desde dentro, a produção de conhecimento. Diante do convite e do aceite, dois docentes iniciaram as redes de entrevistas. O primeiro, do sexo masculino, formado em Artes, atuante na jornada ampliada desde 2010 e com experiência em duas unidades escolares diferentes. O segundo, do sexo feminino, com formação em Pedagogia, atuou por quatro anos na jornada ampliada até o fim do ano letivo de 2012, passando a exercer sua profissão na jornada regular e na educação infantil, estando, portanto, distanciada da dinâmica desta experiência por alguns anos.

Desta maneira, as escolhas dos docentes para as primeiras entrevistas promoveram condições efetivas para contemplar uma multiplicidade de variáveis do universo dos sujeitos da pesquisa. Mais uma vez, assumiu-se o caráter da diversidade como norteador para essa composição, com significativo afastamento dos riscos de uma centralidade homogênea (BAUDRILLARD, 2002; HAN, 2015), que porventura pudesse trazer uma condição limitada à percepção das nuances participantes da construção identitária deste grupo de profissionais.

Os dois "pontos zero" (MEIHY, 1998) como se denomina em história oral o primeiro entrevistado de cada rede, ponto de partida das entrevistas, constituíram-se por professores de singulares que em diferentes aspectos asseguravam o atendimento à diversidade. Além da ocorrência da intersecção, as redes abarcaram quatro das onze escolas que possuem oferta da extensão da jornada e professores de três áreas de formação diferentes.

\section{NARRADORES EM REDE}

Mesmo tendo sido estabelecido um início duplo, a proposta da tessitura das redes manteve-se aberta às possíveis intersecções na medida em que fossem realizadas as indicações dos colaboradores. Assim, a intersecção entre as redes ocorreu, mostrando convergência de argumentos comuns a toda experiência. 
A primeira rede compôs-se com três docentes que somavam sete, quatro e nove anos de experiência na jornada ampliada. A segunda rede, com o mesmo número de integrantes, formou-se com um profissional com quatro anos e outros dois com nove anos de experiência. Isso mostrou que a quantidade de anos de experiência não foi definidora do envolvimento e da identidade estabelecida pelos professores com o projeto. Ou seja, aspectos quantitativos (de maior tempo de permanência no projeto) não são os únicos que devem ser levados em conta. Pessoas que se identificaram com o projeto, mesmo tendo vivenciado por menor tempo, podem pelas indicações se tornarem porta-vozes do grupo. Entretanto, ambas as redes iniciadas, acabaram por indicar uma docente, que acumula nove anos de experiência na jornada ampliada de uma única escola, ocupando assim de forma singular uma centralidade. Mostrando também que há uma consonância na forma de pensar e que o tempo de atuação junto ao projeto compõe elemento a ser considerado, se não para a identidade, para a própria continuidade do projeto.

Figura 1 - Redes de entrevistas.

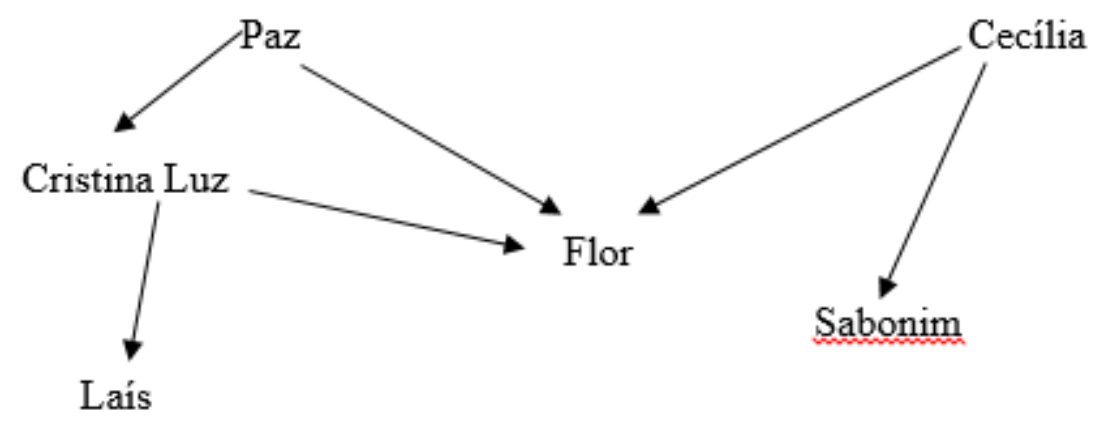

Fonte: Pesquisa "Narrativas em rede: argumentos coletivos e histórias de vida na educação" (OLIVEIRA, 2018).

Os três docentes integrantes da primeira rede são migrantes. Na juventude, em busca de oportunidades referentes ao estudo e ao trabalho se mudaram para essa cidade valeparaibana. Em contrapartida, os três docentes compositores da segunda rede são naturais do município e mantêm fortes referências a uma mesma região da cidade, na qual ainda são moradores e trabalhadores.

As entrevistas da primeira rede aconteceram cada uma em um espaço diferente, sendo, duas em ambientes de trabalho e uma, na residência da colaboradora. Além da facilidade de deslocamento, tais escolhas aparentemente se deram pelo fato de que esses espaços, territórios já conhecidos, também lhes oferecesse relativo conforto e segurança no exercício que se dispunham ao narrar suas histórias de vida. No que se refere aos integrantes da segunda rede, todos os três elegeram a casa da pesquisadora como o espaço para a entrevista. Tal escolha 
sugeriu curiosidade, pois não era um ambiente com o qual conviviam, entretanto a localização desta casa situa-se na região próxima à referências citadas na entrevista, de forma que forma que o próprio trajeto do deslocamento pôde ser usado como recurso de ativação da memória e o desfrute de referências comuns com a pesquisadora para prover fluidez nas possíveis descrições em suas narrativas.

A primeira rede foi iniciada por Paz, um docente que atua na jornada ampliada por sete anos. Ele é efetivo das redes municipal e estadual fato que o coloca diante de realidades e faixas etárias distintas. Narrou sobre sua experiência discente na rede pública e na rede particular. Sua narrativa também aponta que a carreira da docência não era sua proposta profissional de vida. Entretanto, posta a condição, ele fez-se professor, sendo professor. Relatou sobre o início de carreira profissional em um contexto conturbado pela vulnerabilidade social da comunidade atendida e outras tantas experiências docentes. Tratou de contar entre suas descobertas, os seus saberes docentes. Esse professor acabou por indicar outras duas profissionais para compor essa rede de entrevistas: Cristina Luz e Flor.

Ao realizar o contato com Cristina Luz para ser feito o convite à participação da rede de entrevista e ao aceitar tal desafio, a profissional indicou outras duas professoras como potenciais ao estudo. As indicações foram afinadas com os propósitos do estudo, pois permitiam entrevistar professoras graduadas em áreas diferentes, que tinham atuado em unidades escolares distintas e que também se encontravam em situação diferenciada em relação ao projeto: uma atuante e outra, já por alguns anos fora desse contexto. Além disso, uma dessas indicações feitas por Cristina Luz coincidia com a indicação feita por Paz. Apesar dos aceites aos convites por parte de todas, as datas das entrevistas não seguiram a ordem das indicações, visto que, naquele momento, vivia-se o ritmo impresso pelo final do ano letivo demandando certa complexidade nos ajustes de agendas.

Cristina Luz, formada em Biologia, possui o maior tempo de experiência na jornada ampliada. Contou ter ocupado diferentes cargos dentro do projeto, fato que considera uma condição privilegiada para reflexão acerca da jornada ampliada.

A professora Laís viveu a experiência da jornada ampliada durante quatro anos, os primeiros de sua carreira profissional. Desde que se efetivou na rede municipal, passou a exercer sua profissão na jornada regular como professora de Ciências, em diferentes escolas. Narrou que ainda mantem em sua prática preceitos sustentados na jornada ampliada, mostrando o quanto esta experiência foi conformadora de sua identidade profissional.

A segunda rede foi iniciada pela docente que escolheu Cecília como seu codinome. Ela também viveu os primeiros quatro anos da sua carreira no contexto da jornada ampliada e desde 
2013 atua em outros contextos. Dentre os entrevistados, foi a única que declarou ter a docência como sua primeira opção de carreira profissional. Contou suas experiências como professora da jornada ampliada em duas escolas distintas e seus impasses ao atuar na jornada regular. Apesar de não estar mais no contexto da jornada ampliada afirmou enxergar em sua prática muito daquilo que viveu como uma docente envolvida no projeto. Mostrando as marcas da experiência em sua identidade profissional. Cecília indicou dois outros professores para compor a rede de entrevistas e uma das suas indicações também recaía sobre a mesma profissional indicada por Paz e Cristina Luz.

O professor Sabonin foi o segundo entrevistado da segunda rede. Ele também viveu a implantação do projeto em uma unidade escolar e compartilhou alguns anos de trabalho na mesma escola de Cecília. Acumulando uma experiência com a jornada ampliada desde 2009, atuou em escolas e áreas distintas. Durante o tempo em que atuava como professor do projeto, cursou uma segunda licenciatura, fato que lhe abriu novas possibilidades de atuação na jornada ampliada. Em sua narrativa, entre diversas vivências, contou sua experiência de ser professor eventual no ensino regular, no início do ano letivo, enquanto aguardava as atribuições das aulas referentes à jornada ampliada. E, ao falar isso, mostrou sua preferência pela atuação junto à jornada ampliada.

Flor foi a profissional que se traduziu como a intersecção entre as redes, sendo indicada por Paz, Cristina Flor e Cecília e traduzindo-se como uma professora que reuniu atributos para o grupo de colaboradores. Assim como Paz, Flor atua na rede municipal e estadual como professora efetiva. Participou da implantação da jornada ampliada junto com Sabonim e Cecília. Narrou que foi no trabalho com a jornada ampliada que obteve clareza a respeito da Arte como sua formação profissional e, então, pôs-se a cursar uma segunda licenciatura. Possui experiência de jornada ampliada em apenas uma unidade escolar.

Verificamos que cada rede foi composta por profissionais que compartilharam o trabalho em uma mesma unidade escolar por determinado tempo. Flor recebeu indicações que não correspondem a essa condição, mas Cristina Luz, sendo liderança no projeto, conhece o trabalho de todas as unidades escolares do projeto e, que, Paz, formado na mesma área de conhecimento, participa dos mesmos encontros formativos com ela.

Nas narrativas, concepções se convergem e se sugerem como contornos identitários de uma comunidade (BAUMAN, 2003), baseadas em memórias coletivas, compartilhadas de experiências comuns (HALBWACH, 2013). As ideias narradas pelos colaboradores foram sendo reforçadas ou completadas na sequência pelos profissionais indicados. Além disso, as 
duas redes constituídas se agregaram em muitos pontos, formando um único conjunto. A compreensão do trabalho dentro do projeto de escola integral é um deles.

“Os aspectos mais significativos do projeto de educação integral para mim são as possibilidades de uma expansão dos saberes de uma forma diferenciada", afirmou Paz. A exposição feita pelo professor encontrou reforços na narrativa de Cristina Luz, mostrando que os argumentos se apresentam e se reforçam nas indicações da rede:

\section{A educação deveria ter um olhar mais integral. [costumeiramente] Ela visa só algumas janelinhas, mas existem outras e a gente acaba ignorando por uma questão de formalidade, por uma questão de imposição até da nossa própria história. Dentro da escola integral você percebe que pode atingir o menino de outra maneira. (Cristina Luz).}

Laís, integrante da mesma rede, assinalou o fato do professor "ver o ser humano como integral, olhar e ver que é preciso desenvolvê-lo nas questões cognitivas, sociais, nas habilidades físicas e emocionais" como o ponto de maior relevância no projeto. Desta forma, Paz, Cristina Luz e Laís, sustentam um mesmo argumento e uma mesma concepção em relação ao projeto de que a integralidade do ser humano - aluno e professor - estão ligadas à integralidade dos saberes e da educação.

A segunda rede apresentou-se como confirmação do argumento geral da primeira, mas abordou um aspecto específico, que foi a questão da organização do conhecimento formal sobre os seres humanos e sobre o que ensinamos na escola. Para Cecília, o trabalho com a educação integral consiste em "enxergar a criança, a pessoa como um ser biopsicossocial, possuidor de um lado psicológico e um lado biológico e se incomodar com outros setores da vida. Enxergar como um ser completo". A narrativa de Cecília também foi ratificada pelas reflexões de Sabonim: "Por que tem que estudar só essas disciplinas? Só isso faz a diferença para o aluno fora da escola?" Finalizando, uma série de indagações acerca da educação, Sabonim assinalou: "Então, é um todo! Ensinar tudo".

A resposta encontrada pelo professor se conforma com todos os outros pronunciamentos anteriores, demonstrando comprometimento de formação integral dos alunos. Ou seja, reforça o argumento central de sua rede, ao trazer elementos e arrazoados que apresentam a mesma questão sobre outro ponto de vista. A integralidade da educação parece ser defendida pelo conjunto dos professores por ser coerente com a integralidade do ser humano, com a integralidade do saber, com a integralidade das formas de aprender, e com a insuficiência das disciplinas para a construção de um conhecimento para aplicável para a vida.

Flor, que é "colaboradora-elo" entre as redes, desempenhando seu papel, uniu em sua narrativa os argumentos de todos ao dizer: "A educação integral tem uma função muito grande, 
porque ela abrange a ideia de pensar no ser como um todo, desse autoconhecimento, de se conhecer e conhecer o outro". Em tom dedutivo, apontou a forte questão relacional que pensar a integralidade propõe. Desta forma, um novo argumento se soma à discussão da educação integral, e maneira a reforçar sua importância e valorizar sua existência para os alunos e para as experiências de vida e de docência dos colaboradores da pesquisa.

Assim, pode-se notar que os destaques das narrativas apresentam pareceres comuns e admitem coerência e sentido para esse grupo que revela uma identidade compartilhada, como assinalado por Bauman (2003), de forma que os sujeitos entrevistados se mostram imersos em estruturas que os diferenciam de outros grupos. Paz, no decorrer da sua narrativa afirmou: “Aqui, muita coisa é diferente: própria estrutura física, a forma de se fazer as coisas, a dedicação aos estudos e as tentativas de coloca-las em prática, a rotina".

Laís, usando da comparação das experiências docentes que possui, e estabelecendo a diferença entre as identidades do professor que atua no ensino regular e o que atua na jornada ampliada, contou que "no regular é cada um no seu quadradinho, cada um faz do jeito que quer e na hora que quer e dá a sua aula da sua forma. Na jornada ampliada não! Tem que estar todo mundo articulado. Se não tiver todo mundo articulado, não funciona”.

Também estabelecendo uma comparação entre as duas realidades, Cristina Luz narrou:

Não gostaria que fosse diferente o trabalho na jornada ampliada e no regular, mas é! Vejo fora da jornada ampliada um trabalho muito quanto à escolarização, ao conhecimento acadêmico. Não que isso não caiba na jornada ampliada, pois também cabe. Mas acho que a questão de gente com gente, de pessoa com pessoa, se tornou muito mais efetiva dentro da jornada ampliada do que fora dela. (Cristina Luz).

Cecília, ao falar da sua experiência docente no ensino regular logo após sua saída do projeto contou sobre dificuldades de apoio e parcerias ao propor outras formas de ensinar e aprender: "Então, a equipe gestora passava e via aquela sala agitada, sem organização formal das carteiras e julgava que aquilo era uma bagunça, o que chateava. Ficava me cobrando, com vontade de fazer diferente, mas sozinha, sozinha”. A saída encontrada pela docente foi trabalhar na educação infantil, porque declarou ter pegado "ranço do regular". Cecília assinalou:

Assim, meu trabalho acontecia de forma mais lúdica, mais parecido com o trabalho
da jornada ampliada. Esse jeito de trabalhar é mais válido e os aprendizados são muito
mais significativos para os alunos e para a gente também. É muito prazeroso trabalhar
com base em um tema, esmiuçar e encontrar nele as áreas do conhecimento. (Cecília).

Todo início de ano, Sabonim trabalha como professor eventual, substituindo professores do ensino regular. "Me sinto amarrado", declarou o profissional sobre esse período, justificando que na jornada ampliada "o contexto de trabalho é muito diferente do regular". 
Flor, comentando sobre suas vivências profissionais posteriores a da jornada ampliada assinalou: "Quando eu estava no regular, tive a certeza de que eu não queria trabalhar daquele jeito".

Tais expressões narradas nos remetem à Hall (2000) quando afirma que as identidades são constituídas por meio das percepções das diferenças. As compreensões diferentes, marcando as práticas e a rotina, conferem aos colaboradores construções identitárias e compromissos aliados com uma educação de referências mais amplas. Além disso, revela-se a importância da experiência para a organização desta identidade docente, de forma que nas palavras de Nóvoa (1995) “diz-me como ensinas, dir-te-ei quem és”. Considerando os trechos das narrativas, estampa-se a estreita relação entre vivência e construção de saberes, entre profissionalidade e vida, tão bem assinaladas pelo teórico.

\section{APONTAMENTOS FINAIS}

Por meio do registro das histórias de vida pudemos ter acesso a elementos únicos. Acreditamos que elas foram portadoras daquilo que seria bastante difícil a outros tipos de documentos, pois nela somaram-se ingredientes que transitam entre corpo, memória, emoção e histórias. Apesar de apresentar singularidades, as histórias de vida narradas por professores de uma mesma rede transparecem conexões, revelando argumentos coletivos, que nos remetem a memórias coletivas, identidades sociais e comunidades construídas.

Ao longo do texto do artigo, portanto, pudemos apresentar reflexões sobre as redes como elementos teóricos e metodológicos da organização de pesquisas em história oral. Compreendese teoricamente que as redes são manifestações da memória coletiva da comunidade pesquisada (HALBWACHS, 2013), pois os diferentes sujeitos compartilham histórias e significam suas experiências de trabalho. Deste modo, o conceito de memória coletiva estabelece conexões de pertencimento e de diferenciação nas composições identitárias dos professores/professoras, que articulam identidades sociais (POLLAK, 1992), celebram as identidades móveis (HALL, 2006) e constroem comunidades nas quais podem se proteger e se enraizar (BAUMAN, 2003). Sempre levando em conta que as redes são responsáveis por unir subjetividades (GUATARRI, 2012) e produzir intersubjetividades (BUBER, 1977).

Por outro lado, metodologicamente, o contexto que serviu à produção das redes de entrevistas, os traços de sua composição, os elementos que dizem respeito aos sujeitos que as integram foram base sobre a qual se estruturou toda a pesquisa. Na realização de cada entrevista firmava-se a disparidade assegurada no início. A duplicidade das redes traduziu-se como um 
recurso para a seleção de docentes dotados de reconhecimento perante o grupo e, que, apesar da distinção, as narrativas engendravam pontos de amarração dos fios das redes.

Retomando suas composições, ambas as redes parecem não considerar o tempo de atuação no projeto como definidor de pertencimento. Pode-se dizer que as redes abarcam as diferenças na escola de atuação, parecendo indicar que mais que ações circunscritas a uma ou outra realidade escolar, o que os une é um projeto de educação baseado no compromisso com uma formação humana, democrática e de reconhecimento das diferenças. Além disso, parece que as redes, também argumentam que estar agora ou não no projeto, é secundário e que as identidades produzidas a partir da vivência junto a ele merecem atenção. Destacando assim, que a identidade e o pertencimento ao projeto se traduz em experiência significativa mesmo para as pessoas que dele não fazem mais parte oficialmente, mas que suas vivências se desdobram e contagiam outros cotidianos escolares.

Fica evidente que o presente trabalho viu e vê esses entrevistados em rede. Mas, gostaríamos de destacar que as pessoas também compreendem seu grupo em rede. A experiência do registro das histórias de vida mostrou o pertencimento a esse grupo e as relações estabelecidas entre cada um dos sujeitos. A rede, portanto, foi organizada e visualizada por meio do conhecimento e a participação desses colaboradores.

Do início da pesquisa até o momento é preciso ter claro que partimos de um conceito teórico metodológico, em que as entrevistadoras tinham uma visão quase operacional de uma primeira rede. Durante o processo de pesquisa foram se montando duas outras redes a partir das indicações de cada ponto zero (com as visões dos diferentes sujeitos entrevistados), apontando a pluralidade das identidades docentes e dos universos escolares. Por fim, podemos compreender que os pesquisadores, ao retornar os conhecimentos aos diferentes sujeitos, compuseram uma nova - e quarta - rede. De forma que cada um em seu "pedacinho" pode agora se ver como pontos de amarração de uma teia, e que em conjunto passa a conhecer visões e construir opiniões mescladas de subjetividades das pesquisadoras e dos colaboradores. $\mathrm{Ou}$ seja, pode-se dizer que o próprio processo de pesquisa formou uma rede ampla que compõe todas as outras.

Além disso, é preciso reconhecer a importância da sistematização do registro e da documentação sobre as experiências de vida dos professores, feita a partir da pesquisa. Tais registros são fundamentais para se entender as transformações. Assim o registro se caracteriza como uma fotografia deste momento da experiência e da vida desses docentes. Ao mesmo tempo em que registra, cria uma história que, partilhada, cria alicerces para as mudanças necessárias. Outro aspecto é que tais registros despertam a autoconsciência, pois entendemos 
que o próprio contar de suas histórias é um ato reflexivo. Nóvoa (1995) defende que esses são momentos de formação e que devem ser continuamente reforçados e estimulados.

A presente pesquisa proporcionou uma escuta ativa e de acolhimento. Neste sentido, cabe lembrar que de acordo com o trabalho de Cecília Warschauer (2001, 2004), esta escuta é algo que a rede possibilita. A consciência de sua história e de estar em rede produz espaço de acolhimento no qual é possível compartilhar e aprender. Assim, o ato de fazer o registro é também o de montar rede e compartilhar argumentos e experiências que possam unir pessoalprofissional, superando a racionalidade que separa as emoções e o pensamento, vida e exercício profissional.

O conjunto das narrativas cotidianas revela, portanto, o percurso da construção identitária destes profissionais que se dedicaram em um fazer de sua profissão dentro de uma dinâmica diferenciada do que se convenciona no ambiente escolar. A trilha percorrida, enquanto se formavam as redes, foi desafiadora e causadora de boas surpresas que se engendraram pela dedicação dos docentes em colaborar com a pesquisa, demonstrando grande disposição em narrar suas histórias. Assim, podemos compreender que o uso das redes permitiu acesso a trocas subjetivas e a construções intersubjetivas, que mostraram a diversidade de nossos colaboradores e a construção de seus argumentos identitários em torno da defesa da educação integral. Isso nos remete a uma faceta contemporânea da história da educação e passa a ser patrimônio educativo de nossa sociedade.

\section{REFERÊNCIAS}

BAUDRILLARD, J. A troca impossível. Rio de Janeiro: Nova Fronteira, 2002.

BAUMAN, Z. Comunidade: a busca por segurança no mundo atual. Rio de Janeiro: Jorge Zahar Editor, 2003.

BENJAMIN, W. O narrador: observações acerca da obra de Nicolau Lescov. In: Obras escolhidas: magia e técnica, arte e política. São Paulo: Brasiliense, 1985.

BUBER, M. Eu e tu. São Paulo: Moraes; 1977.

Do diálogo e do dialógico. São Paulo: Perspectiva; 1982.

DELEUZE, G.; GUATTARI, F. Mil platôs: capitalismo e esquizofrenia. Rio de Janeiro: Ed. 34, 1995.

GUATTARI, F. As três ecologias. São Paulo: Papirus, 2000. 
. Caosmose: um novo paradigma estético. 2. ed. São Paulo: Ed. 34, 2012.

HALBWACHS, M. A memória coletiva. São Paulo: Centauro, 2013.

HALL, S. Identidades Culturais na Pós-Modernidade. Rio de Janeiro: DP\&A, 2006.

Quem precisa de identidade? In: SILVA, T. T. da. (Org.). Identidade e diferença: a perspectiva dos estudos culturais. Petrópolis, RJ: Vozes, 2000. p.103-133.

HAN, B. C. Sociedade do cansaço. Petrópolis-RJ, Vozes, 2015.

MEIHY, J. C. S. B. Canto de morte Kaiowá: história oral de vida. São Paulo: Edições Loyola, 1991.

Manual de história oral. São Paulo: Edições Loyola, 1998; 2005.

; HOLANDA, F. História oral: como fazer, como pensar. São Paulo: Contexto, 2007.

; RIBEIRO S. L. S. Guia prático de história oral: para empresas, universidades, comunidades, famílias. São Paulo: Contexto, 2011.

NÓVOA, A. A Formação contínua entre a pessoa-professor e a organização-escola. Inovação, Lisboa: Instituto de Inovação Educacional, v. 4, n. 1, p. 63-76, 1991.

. Diz-me como ensinas, dir-te-ei quem és e vice-versa. In: FAZENDA, Ivani. A pesquisa em educação e as transformações do conhecimento. Campinas: Papirus, 1995. p. $29-41$.

POLLAK, M. Memória e identidade social. Revista Estudos Históricos, Rio de Janeiro, v. 5, n. 10, p. 200-212, 1992.

RIBEIRO, S. L. S. Apresentação: Dossiê "História Oral e Memória". História oral e a consolidação de um campo de pesquisa. Revista Outras Fronteiras, Cuiabá-MT, v. 3, n. 1, jan./jun. 2016.

SARLO, B. Tempo passado: cultura da memória e guinada subjetiva. São Paulo: UFMG; Cia. das Letras, 2007.

WARSCHAUER, C. Rodas em Rede: oportunidades formativas na escola e fora dela. São Paulo: Paz e Terra, 2001.

Rodas e narrativas: caminhos para a autoria de pensamento, para a inclusão e a formação. In: SCOZ, Beatriz et al. (org). Psicopedagogia: contribuições para a educação pósmoderna. Petrópolis: Vozes, 2004. p. 13-23. 